\title{
Impacts of ocean current-atmosphere interactions on mesoscale eddy energetics in the Kuroshio extension region
}

\author{
Xuan Shan ${ }^{*}$, Zhao Jing, Bingrong Sun and Lixin Wu
}

\begin{abstract}
The surface ocean current's imprint on the wind stress (known as the current feedback) has a significant influence on the wind power input to the ocean. In this study, we investigate the effect of the current feedback on mesoscale eddy energetics in the Kuroshio extension region using a high-resolution $(9 \mathrm{~km})$ coupled regional climate model. We perform three sets of simulations: one calculates the wind stress without the surface current, one includes only the mesoscale eddy's current and another includes the entire current in the computation. In this way, the mesoscale eddy's current feedback can be isolated and its contribution to the entire current feedback can be assessed. The simulation results show that the mesoscale eddy's current feedback results in negative wind power input to mesoscale eddies and reduces the surface eddy kinetic energy (EKE) by 20\% in the Kuroshio extension region. This negative wind power is compensated primarily by the enhanced conversion from mean flow kinetic energy (MKE) and eddy potential energy (EPE) to EKE and secondarily by the reduced pressure flux divergence and horizontal dissipation. Compared to the mesoscale eddy's current feedback, the entire current feedback has a similar impact on EKE and the wind power on mesoscale eddies, while it affects the EKE budget differently. It weakens the MKE to EKE conversion partly due to the reduced kinetic energy input to background flows by wind. Correspondingly, the negative wind power on mesoscale eddies is primarily compensated by the enhanced EPE to EKE conversion.
\end{abstract}

Keywords: Current feedback, Mesoscale eddy energetics, Kuroshio extension

\section{Introduction}

Ocean mesoscale eddies interact strongly with the overlying atmosphere. The impact of such interactions on eddies themselves has been extensively analyzed in the past decade. Sea surface temperature anomalies (SSTAs) associated with mesoscale eddies are the dominant driver of surface heat flux anomalies at mesoscale, with cold and warm eddies inducing anomalous heat into and out of the ocean, respectively (e.g., Kirtman et al. 2012; Ma et al. 2016; Bishop et al. 2017; Li et al. 2017; Yang et al. 2018). These processes act to damp the mesoscale SSTAs and thus result in the destruction of the eddy available

*Correspondence: xuan_shan@outlook.com Key Laboratory of Physical Oceanography/Institute for Advanced Ocean Studies, Ocean University of China and Qingdao National Laboratory for Marine Science and Technology, Qingdao, China potential energy (EPE) (Ma et al. 2016; Shan et al. 2020). Moreover, the mesoscale eddy-induced heat anomalies affect the stability of the atmospheric boundary layer and the vertical turbulent momentum transfer, accelerating (decelerating) the surface wind over warm (cold) eddies (e.g., Park and Cornillon 2002; Vecchi et al. 2004; Xie 2004; Chelton and Xie 2010; O'Neill et al. 2010, 2012; Frenger et al. 2013). Such SSTA-driven wind anomalies lead to a dipole structure in the wind stress curls over mesoscale eddies, influencing the eddy propagation through Ekman pumping (e.g., Dewar and Flierl 1987; Gaube et al. 2015; Seo et al. 2016).

In addition to SSTAs, the ocean surface current is another signature felt by the overlying atmosphere as the surface wind stress is determined by the vector difference between wind and current instead of wind 
itself. With the advent of radar scatterometers, smallscale features in the wind stress induced by the ocean current can be seen clearly (Cornillon and Park 2001; Kelly et al. 2001; Chelton et al. 2004). Including the ocean current in the wind stress formulation (known as the current feedback; e.g., Dawe and Thompson 2006; Renault et al. 2016) leaves a significant influence on the wind power input to the ocean. Plenty of literatures using both observations and model simulations reveal that the current feedback reduces the wind power input to the ocean by $20-35 \%$ (e.g., Dawe and Thompson 2006; Duhaut and Straub 2006; Zhai and Greatbatch 2007; Hughes and Wilson 2008; Xu and Scott 2008). This reduction is attributed to the decreased positive wind power input to large-scale background flows and the negative wind power input to mesoscale eddies, with the latter more dominant (e.g., Xu and Scott 2008; Renault et al. 2016; Seo et al. 2016).

It has been well recognized that the eddy kinetic energy (EKE) is weakened in response to the current feedback. Numerical simulations suggest that including ocean currents in the wind stress computation results in a $10-55 \%$ reduction of the surface EKE compared to that of not (Zhai and Greatbatch 2007; Renault et al. 2016; Seo et al. 2016; Oerder et al. 2018). Yet it is barely known how the EKE budget responds to the current feedback to rebuild the equilibrium state of EKE. Should the eddy-mean flow energy exchange and/or other EKE destruction processes adjust to compensate the EKE loss through the current feedback? Insight into this question is important as it does not only help in understanding the influence of the current feedback on EKE, but also on the eddy-mean flow interaction that is crucial for shaping ocean circulations and the ocean stratification.

The Kuroshio extension region is featured by energetic mesoscale eddies and strong atmospheric storms. Despite a hotspot for mesoscale ocean-atmosphere interactions, the impact of the current feedback on eddy energetics, to the best of our knowledge, has not be assessed and will be evaluated in this study based on a high-resolution coupled regional climate model. We remark that it is necessary to use a coupled model, as ocean alone simulations are not capable of representing the ocean current's imprint on the surface wind (Renault et al. 2016) and thus tend to overestimate the current feedback. The remainder of the paper is organized as follows: "Method" section provides the detailed description of the methodology. Comparisons of EKE and its budget in simulations with and without the current feedback will be made in "Results and discussion" section. "Conclusions" section summaries the main results in this study.

\section{Method}

\section{Model description}

The Coupled Regional Climate Model (CRCM) developed at Texas A\&M University and implemented at Pilot National Laboratory for Marine Science and Technology (Qingdao) is used to assess the impact of the current feedback on eddy energetics in the Kuroshio extension region. The model includes the Regional Oceanic Modeling System (ROMS) as the ocean component, the Weather Research and Forecasting Model (WRF) as the atmosphere component, and a coupler that allows the exchanges of heat, freshwater and momentum between ocean and atmosphere components.

The model covers the entire North Pacific from $3.6^{\circ} \mathrm{N}$ to $66^{\circ} \mathrm{N}, 99^{\circ} \mathrm{E}$ to $270^{\circ} \mathrm{E}$, with a horizontal resolution of $9 \mathrm{~km}$ for WRF and ROMS. In our configuration, WRF and ROMS are coupled hourly. WRF gives heat fluxes, freshwater fluxes as well as wind stresses to ROMS, while ROMS provides SST and surface current velocity for WRF. The WRF initial condition is obtained from NCEP-II reanalysis, whereas the ROMS initial condition is obtained from a 6-year spin-up run using CORE-II dataset as the atmospheric forcing. WRF has 32 vertical levels, using YSU scheme for planetary boundary layer (Hong and Pan 1996), RRTMG and Goddard scheme for longwave and shortwave radiation (Chou and Suarez 1994; Mlawer et al. 1997), Lin et al. (1983)'s scheme for microphysics, Smagorinsky scheme for calculating eddy coefficient (Smagorinsky 1963), Kain-Fritsch (KF) scheme for cumulus parameterization (Kain 2004) and Noah scheme for land surface. ROMS has 50 levels in a vertical terrain-following coordinate with the vertical grid size in the upper $100 \mathrm{~m}$ finer than $25 \mathrm{~m}$. We use a K-profile parameterization (KPP) turbulent mixing closure scheme for vertical mixing (Large et al. 1994) and a bi-harmonic Smagorinsky-like mixing for momentum (Griffies and Hallberg 2000). No horizontal mixing parameterization for tracers is applied.

\section{Experiment design}

Three sets of simulations are performed in this study. The only difference among them is the calculation of the wind stress. CTRL is a fully coupled simulation in which the wind stress is calculated based on the relative motion of the surface wind and the ocean current:

$$
\boldsymbol{\tau}=\rho_{\mathrm{a}} C_{\mathrm{d}}(\mathbf{W}-\mathbf{U})|\mathbf{W}-\mathbf{U}|,
$$

where $\tau$ is the wind stress, $\rho_{\mathrm{a}}$ is the air density, $C_{\mathrm{d}}$ is the drag coefficient, $\mathbf{W}$ is the $10-\mathrm{m}$ wind and $\mathbf{U}$ is the surface current. In noU $U_{\text {tot }}$, the entire surface current is excluded in the wind stress calculation, as was usually done in previous studies concerning the current feedback (e.g., Duhaut and Straub 2006; Zhai and Greatbatch 2007; 
Renault et al. 2016, 2019). The results of Seo et al. (2016) show that the current feedback-induced EKE reduction can be largely ascribed to the influence of the mesoscale eddy's current feedback in the California Current system. In order to test to what extent the impacts of the current feedback on eddy energetics can be explained by the mesoscale current's effects in the Kuroshio extension region, we perform the $\mathrm{noU}_{\mathrm{e}}$ experiment to isolate the mesoscale eddy's current feedback. In noU $\mathrm{e}_{\mathrm{e}}$ a low-pass Loess filter with a $15^{\circ}$ (longitude) $\times 5^{\circ}$ (latitude) half width is implemented to the ROMS simulated surface current before given to WRF at each coupling step. Thus the mesoscale eddy's current is removed in the wind stress calculation, whereas the background flow's current is retained. All the three sets of experiments consist of an ensemble of five half-year simulations. They are initialized on 1 October 2003, 2004, 2005, 2006 and 2007, respectively, then integrated for 6 months. The winter season is chosen due to the intense air-sea interactions during that time.

\section{EKE budget}

Decomposing motions into large-scale background flows (denoted by overbars) and mesoscale eddies (denoted by primes), the budget of EKE can be expressed as: is the reference density, $g=9.8 \mathrm{~m} \mathrm{~s}^{-2}$ is the gravitational acceleration, $K_{\mathrm{V}}$ is the vertical viscosity coefficient, and $K_{\mathrm{H}}\left(K_{4}\right)$ is the horizonal viscosity coefficient. The largescale and mesoscale motions in the subsequent analyses are separated by a 2-D Gaussian filter. This filter performs similarly with the $15^{\circ}$ (longitude) $\times 5^{\circ}$ (latitude) Loess filter by choosing suitable parameters but carries a much smaller computational burden (see Additional file 1: Figure $\mathrm{S} 1$ ).

The term on the left-hand side of Eq. (2) corresponds to the tendency of EKE (referred to as $\mathrm{TK}_{\mathrm{e}}$ ). The first term on the right-hand side (RHS) describes the advection of EKE. The second term denotes the eddy-induced momentum flux acting on the velocity gradient of background flows. These two terms tend to cancel each other locally with a net effect of the conversion from kinetic energy of mean flows (MKE) to EKE (referred to as $K_{\mathrm{m}} K_{\mathrm{e}}$ ). The third term shows the energy divergence through the pressure flux (referred to as PWork). The fourth term represents the conversion from EPE to EKE (referred to as $P_{\mathrm{e}} K_{\mathrm{e}}$ ). The fifth and sixth terms denote the vertical and horizontal dissipation of EKE, referred to as $\mathrm{VDK}_{\mathrm{e}}$ and $\mathrm{HDK}_{\mathrm{e}}$, respectively. The last term is the residue due to the

$$
\begin{aligned}
& \underbrace{\left\langle\frac{\partial \mathrm{EKE}}{\partial t}\right\rangle}_{\text {TK }_{\mathrm{e}}}=\underbrace{-\langle\mathbf{u} \cdot \nabla \mathrm{EKE}\rangle-\left\langle\rho_{0} u^{\prime} \mathbf{u}^{\prime} \cdot \nabla \bar{u}+\rho_{0} v^{\prime} \mathbf{u}^{\prime} \cdot \nabla \bar{v}\right\rangle}_{K_{\mathrm{m}} K_{\mathrm{e}}} \underbrace{-\left\langle\nabla \cdot\left(\mathbf{u}^{\prime} p^{\prime}\right)\right\rangle}_{\text {PWork }} \underbrace{-\left\langle w^{\prime} \rho^{\prime} g\right\rangle}_{P_{\mathrm{e}} K_{\mathrm{e}}} \\
& \underbrace{+\left\langle\rho_{0} u^{\prime} \frac{\partial}{\partial z}\left(K_{\mathrm{V}} \frac{\partial u^{\prime}}{\partial z}\right)+\rho_{0} v^{\prime} \frac{\partial}{\partial z}\left(K_{\mathrm{V}} \frac{\partial v^{\prime}}{\partial z}\right)\right\rangle}_{\mathrm{VDK}} \\
& \underbrace{+\left\langle\rho_{0} u^{\prime} K_{H} \nabla_{\mathbf{h}}^{2} u^{\prime}-\rho_{0} u^{\prime} K_{4} \nabla_{\mathbf{h}}^{4} u^{\prime}+\rho_{0} v^{\prime} K_{H} \nabla_{\mathbf{h}}^{2} v^{\prime}-\rho_{0} v^{\prime} K_{4} \nabla_{\mathbf{h}}^{4} v^{\prime}\right\rangle}_{\text {HDKe }} \\
& \underbrace{-\left\langle\rho_{0} u^{\prime} \overline{\mathbf{u}} \cdot \nabla \bar{u}+\rho_{0} v^{\prime} \overline{\mathbf{u}} \cdot \nabla \bar{v}-\rho_{0} u^{\prime} \overline{\mathbf{u} \cdot \nabla u}-\rho_{0} v^{\prime} \overline{\mathbf{u} \cdot \nabla v}\right\rangle}_{\text {residue }},
\end{aligned}
$$

where $\langle\cdots\rangle$ denotes the time and area-mean, $\mathbf{u}=(u, v, w)$ is the three-dimensional ocean current, $\quad E K E=\frac{1}{2} \rho_{0}\left(u^{\prime 2}+v^{\prime 2}\right), \quad \nabla=(\partial / \partial x, \partial / \partial y, \partial / \partial z)$, $\nabla_{\mathbf{h}}=(\partial / \partial x, \partial / \partial y), p$ is the pressure, $\rho_{0}=1025 \mathrm{~kg} \mathrm{~m}^{-3}$ non-orthogonality of the Gaussian filter, which is found to have a minor impact.

The current feedback contributes to the EKE budget through $\mathrm{VDK}_{\mathrm{e}}$. This can be shown by integrating $\mathrm{VDK}_{\mathrm{e}}$ from an arbitrary depth of $z_{\mathrm{b}}$ to the sea surface:

$$
\begin{aligned}
& \left\langle\int_{z_{\mathrm{b}}}^{0}\left[\rho_{0} u^{\prime} \frac{\partial}{\partial z}\left(K_{\mathrm{V}} \frac{\partial u^{\prime}}{\partial z}\right)+\rho_{0} v^{\prime} \frac{\partial}{\partial z}\left(K_{\mathrm{V}} \frac{\partial v^{\prime}}{\partial z}\right)\right] \mathrm{d} z\right\rangle \\
& =\underbrace{\left\langle u_{\mathrm{s}}^{\prime} \tau_{\mathrm{x}}^{\prime}+v_{\mathrm{s}}^{\prime} \tau_{\mathrm{y}}^{\prime}\right\rangle}_{\mathrm{WP}_{\mathrm{e}}} \underbrace{-\left\langle\left.\rho_{0} u^{\prime} K_{\mathrm{V}} \frac{\partial u^{\prime}}{\partial z}\right|_{z=z_{\mathrm{b}}}+\left.\rho_{0} v^{\prime} K_{\mathrm{V}} \frac{\partial v^{\prime}}{\partial z}\right|_{z=z_{\mathrm{b}}}+\int_{z_{\mathrm{b}}}^{0} \rho_{0} K_{\mathrm{V}}\left[\left(\frac{\partial u^{\prime}}{\partial z}\right)^{2}+\left(\frac{\partial v^{\prime}}{\partial z}\right)^{2}\right] \mathrm{d} z\right\rangle}_{\text {VIDK }_{\mathrm{e}}},
\end{aligned}
$$


where $u_{\mathrm{s}}^{\prime}$ and $v_{\mathrm{s}}^{\prime}$ are the mesoscale zonal and meridional surface current, $\tau_{\mathrm{x}}^{\prime}$ and $\tau_{\mathrm{y}}^{\prime}$ are the mesoscale zonal and meridional surface wind stress. The first term on the RHS represents the wind power input to mesoscale eddies (referred to as $\mathrm{WP}_{\mathrm{e}}$ ) that is affected by the current feedback and the remaining denotes vertical interior dissipation (referred to as VIDK $_{\mathrm{e}}$ ).

In the following analysis, we choose $z_{\mathrm{b}}=-3000 \mathrm{~m}$ rather than the depth of sea floor due to its unevenness. As the shallowest sea floor in this region is at $-3893 \mathrm{~m}$, the bottom friction is not included in $\mathrm{VIDK}_{\mathrm{e}}$ but affects the EKE budget indirectly via PWork (Pedloski 1987).

\section{Results and discussion}

\section{Influences of the current feedback on EKE}

Figure $1 \mathrm{a}, \mathrm{b}$ displays the 5 -year wintertime (OctoberMarch) mean surface EKE in CTRL and that derived from the Estimating the Circulation and Climate of the Ocean, Phase II (ECCO2) dataset as a benchmark. The simulation results of CRCM and ECCO2 are generally consistent with each other. Both are featured by high EKE values along the Kuroshio extension, although there is an acceptable northward displacement of the Kuroshio extension in CRCM that is a common problem for regional modeling (e.g., Kang 2008; Seo et al. 2010). In addition, the EKE simulated by CRCM is slightly higher. This may be attributed to the discrepancy of resolution, sampling rate and data processing procedure.

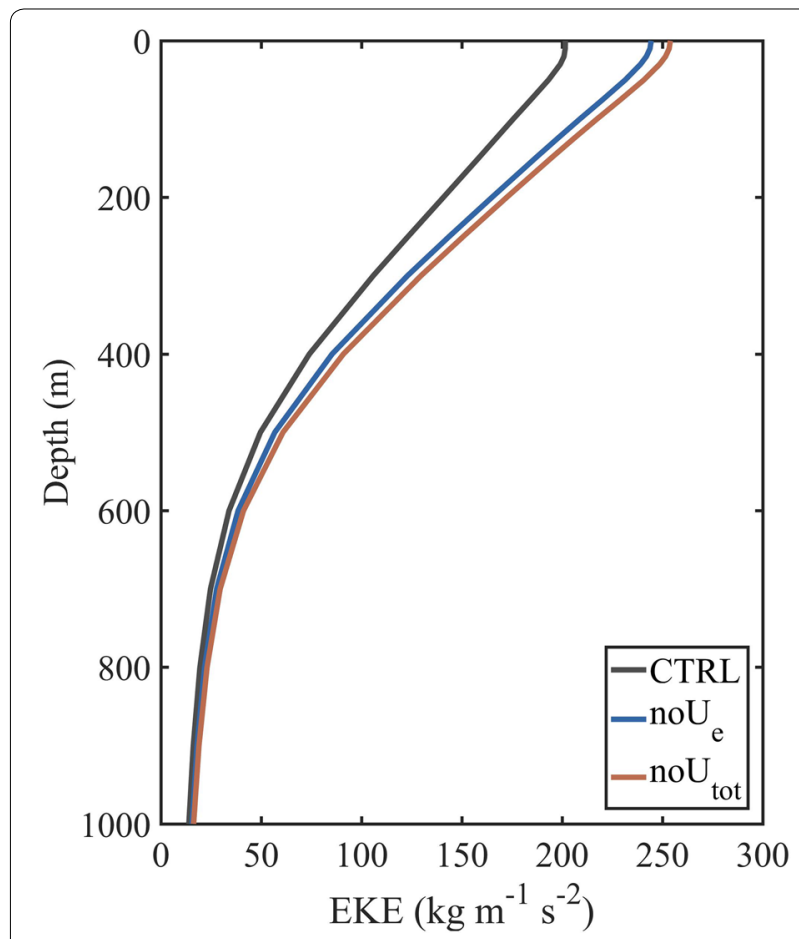

Fig. 2 The 5-year wintertime mean EKE averaged within the Kuroshio

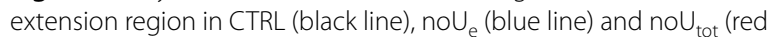
line)

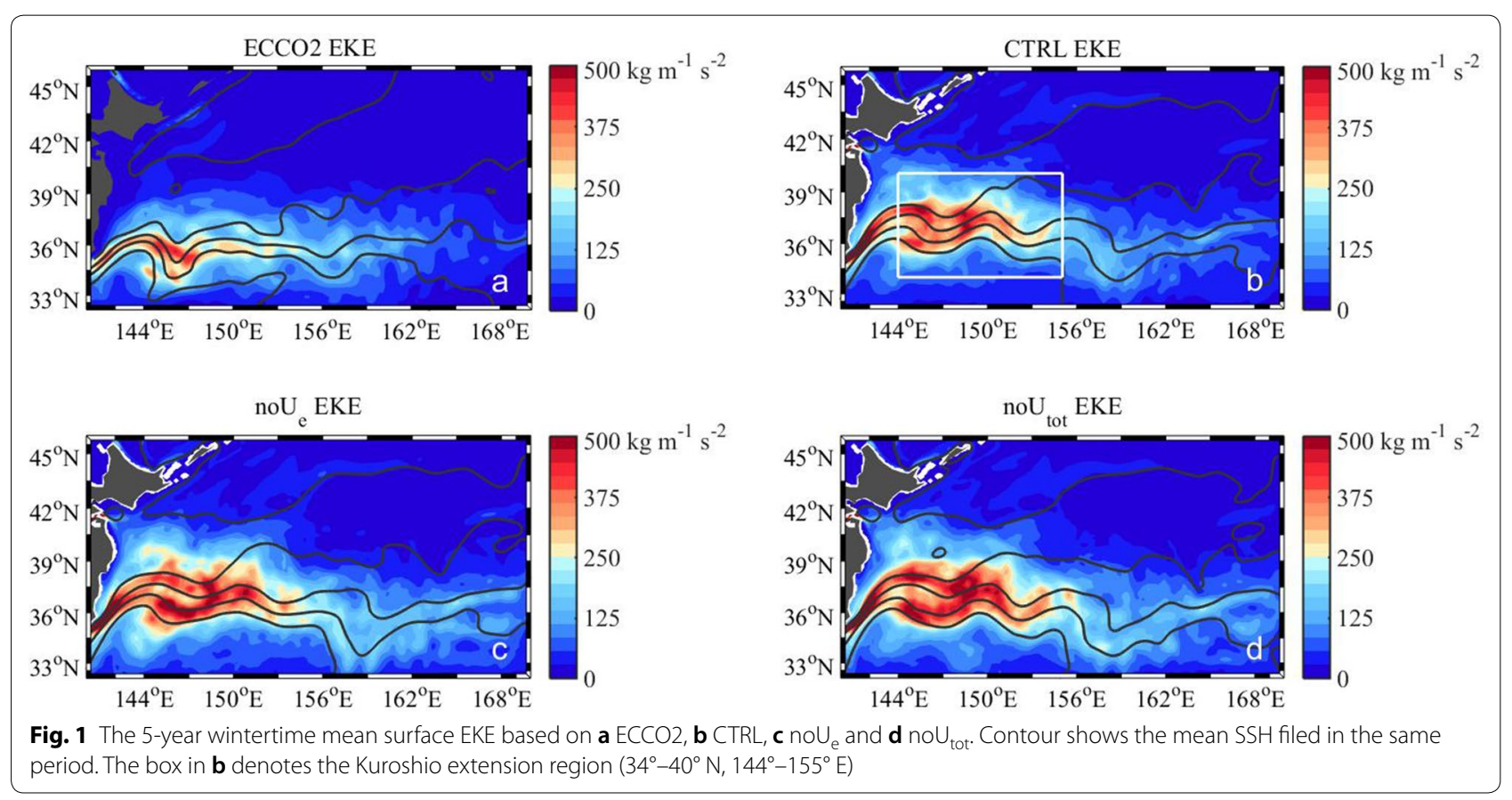


Both of the EKE in noU tot and noU $U_{e}$ exhibit similar spatial distribution, but have evidently higher values compared to that in CTRL (Fig. 1b-d). Figure 2 shows the area-mean EKE in the Kuroshio extension region at different depths. The EKE is surface intensified with an e-folding decaying depth of about $400 \mathrm{~m}$, consistent with the observed eddy structures in this region (Dong et al. 2017). The reduction of EKE in CTRL to those in noU ${ }_{\text {tot }}$ and $\mathrm{noU}_{\mathrm{e}}$ is most evident at the sea surface and diminishes gradually as the depth increases. This is expected given that the difference among these experiments originates from the surface wind power. Consistent with the findings reported by Seo et al. (2016), the mesoscale eddy's current feedback is the main factor resulting in the EKE reduction, as evidenced by the similar EKE values in $\operatorname{noU}_{\text {tot }}$ and noU $_{\mathrm{e}}$.

\section{Influences of the current feedback on the EKE budget}

In order to figure out how ocean internal dynamics responds to the current feedback to rebuild the equilibrium, the EKE budget within the Kuroshio extension region is analyzed. The EKE in CTRL is generated through $K_{\mathrm{m}} K_{\mathrm{e}}$ and $P_{\mathrm{e}} K_{\mathrm{e}}$ while destructed mainly through $\mathrm{VDK}_{\mathrm{e}}, \mathrm{HDK}_{\mathrm{e}}$ and PWork (Table 1). The EKE divergence through the pressure flux is partially due to the horizontal propagation of mesoscale eddies out of the Kuroshio extension region and partly attributed to the downward EKE radiation into the bottom boundary layer to balance the bottom friction. The EKE tendency is an order of magnitude smaller compared to other terms, suggesting that the mesoscale eddies in the Kuroshio extension are almost at the forced-dissipated equilibrium state.

In CTRL, $\mathrm{WP}_{\mathrm{e}}$ is negative as a result of the mesoscale eddy's current feedback (Fig. 3a), whereas the values in $\mathrm{noU}_{\mathrm{e}}$ and $\mathrm{noU}_{\text {tot }}$ are close to zero due to the absence of this feedback (Fig. 3b, c). The responses of EKE budget to the negative $\mathrm{WP}_{\mathrm{e}}$ in CTRL are complicated, involving several terms. Compared to $\operatorname{noU}_{\mathrm{e}}$, the EKE destruction via $\mathrm{HDK}_{\mathrm{e}}$ and PWork weakens due to the reduced EKE in CTRL. But this is not enough to make the EKE budget reach a new equilibrium. As the main sources of EKE, $K_{\mathrm{m}} K_{\mathrm{e}}$ and $P_{\mathrm{e}} K_{\mathrm{e}}$ strengthen evidently. They compensate

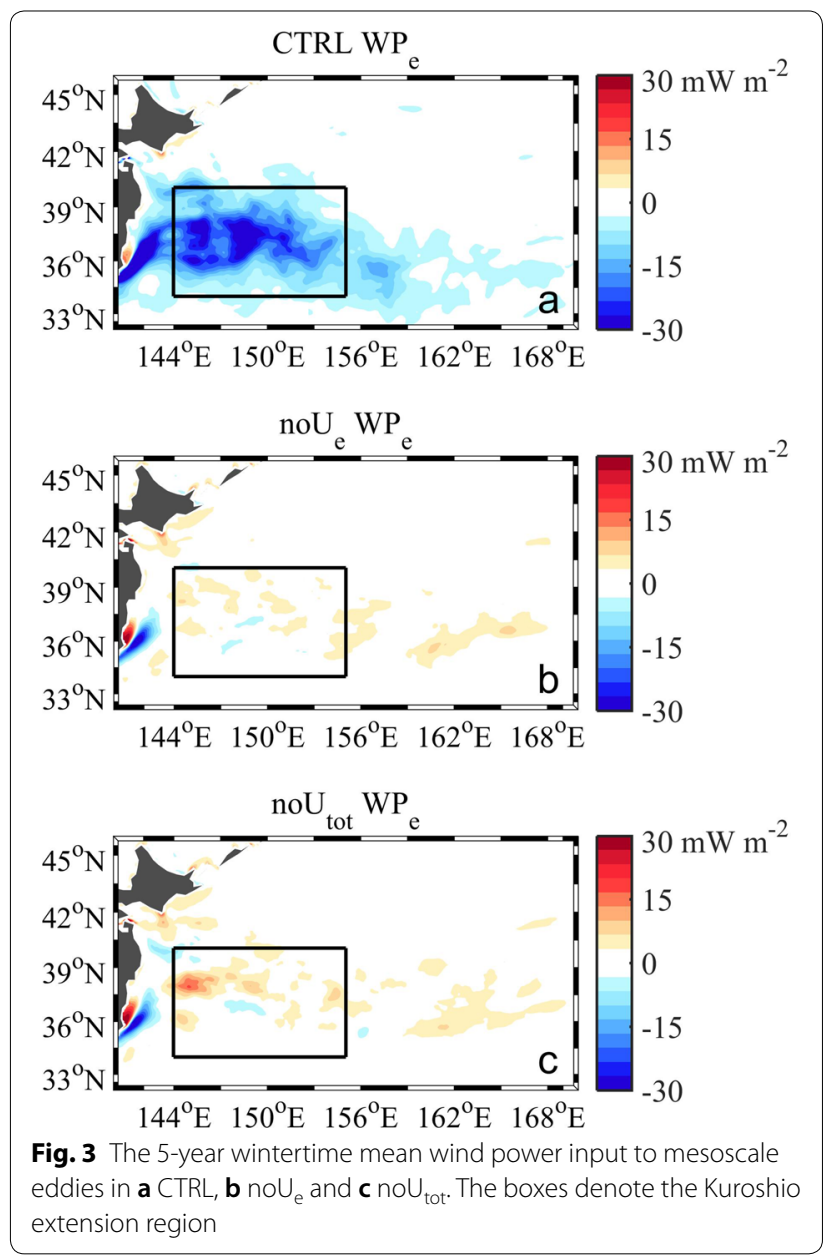

$25 \%$ and $30 \%$ of the EKE deflection through $\mathrm{WP}_{\mathrm{e}}$, respectively.

However, the change of the EKE budget in response to the entire current feedback is different from that to the mesoscale eddy's current feedback. The most noticeable discrepancy between the two feedbacks, DIFF1 $\left.(\text { CTRL-noU })_{\mathrm{e}}\right)$ and DIFF2 (CTRL-noU $\left.{ }_{\text {tot }}\right)$, comes from $K_{\mathrm{m}} K_{\mathrm{e}}$. Specifically, $K_{\mathrm{m}} K_{\mathrm{e}}$ is weakened rather than intensified with the entire current feedback. The influences

Table 1 The upper-3000 $\mathrm{m}$ integrated EKE budget $\left(\mathrm{mW} \mathrm{m}^{-2}\right)$ in the Kuroshio extension region

\begin{tabular}{lrrrrrrr}
\hline & TK $_{\mathbf{e}}$ & PWork & $\boldsymbol{K}_{\mathbf{m}} \boldsymbol{K}_{\mathbf{e}}$ & $\boldsymbol{P}_{\mathbf{e}} \boldsymbol{K}_{\mathbf{e}}$ & VDK $_{\mathbf{e}}\left(\mathbf{W P}_{\mathbf{e}} / \mathbf{V I D K}_{\mathbf{e}}\right)$ & HDK $_{\mathbf{e}}$ & Residue \\
\hline CTRL & 0.26 & -9.82 & 24.01 & 13.64 & $-17.27(-13.17 /-4.10)$ & -6.15 & -4.15 \\
noU $_{e}$ & 1.98 & -12.50 & 20.41 & 9.33 & $-2.73(1.39 /-4.12)$ & -7.29 & -5.24 \\
noU $_{\text {tot }}$ & 2.31 & -13.81 & 26.21 & 5.79 & $-2.22(1.98 /-4.20)$ & -7.70 & -5.96 \\
DIFF1 & -1.72 & 2.68 & 3.60 & 4.31 & $-14.54(-14.56 / 0.02)$ & 1.14 & 1.09 \\
DIFF2 & -2.05 & 3.99 & -2.20 & 7.85 & $-15.05(-15.15 / 0.10)$ & 1.55 & 1.81 \\
\hline
\end{tabular}

DIFF1 (CTRL-noU $)_{\mathrm{e}}$ ) shows the mesoscale eddy's current feedback only. DIFF2 (CTRL-noU ${ }_{\text {tot }}$ ) represents the entire current feedback. All values shown here are the 5-year wintertime mean. The values in the brackets represent $W_{e}$ and $V_{I D K}$ 

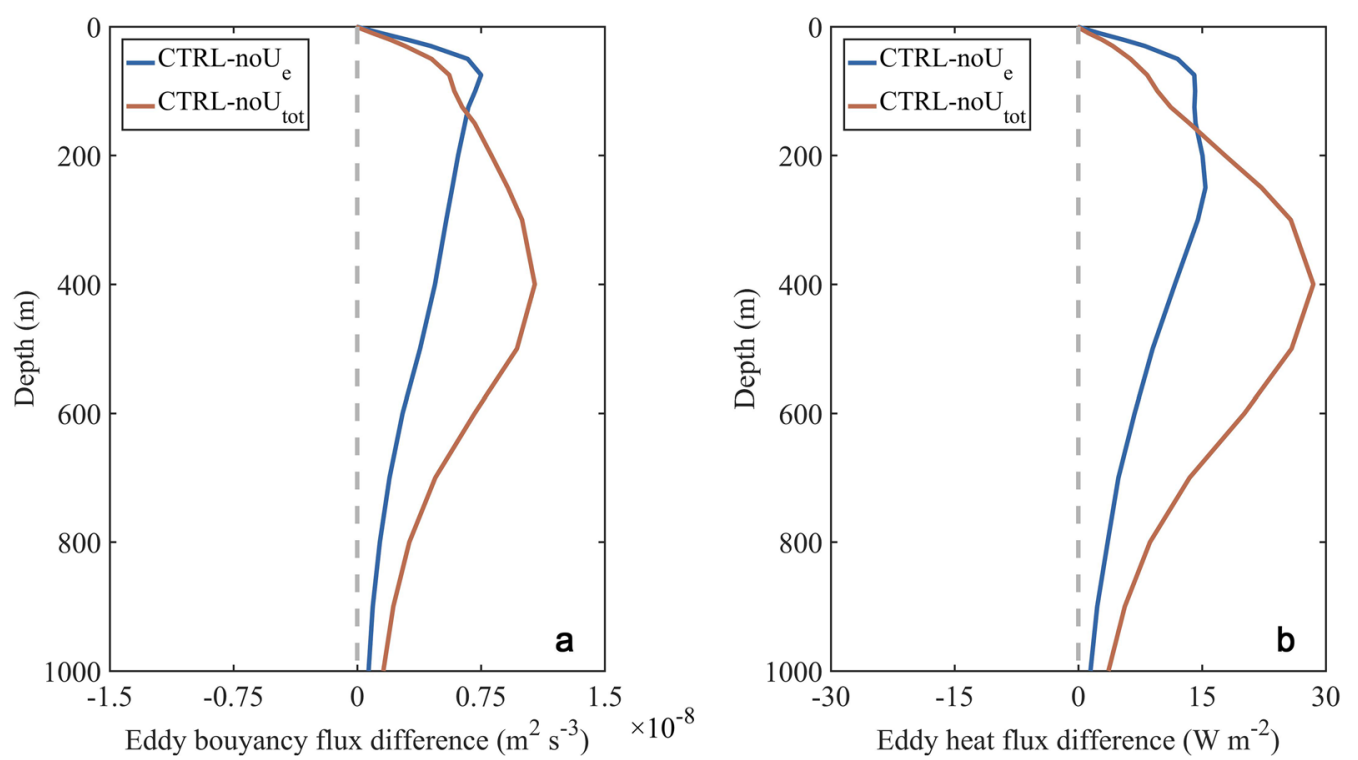

Fig. 4 The difference of 5-year wintertime mean vertical eddy fluxes averaged within the Kuroshio extension region. a Shows the difference of eddy buoyancy fluxes $\left(w^{\prime} b^{\prime}\right)$ between $C T R L$ and noU $\mathrm{U}_{\mathrm{e}}$ (blue line) and that between CTRL and no $\mathrm{U}_{\text {tot }}$ (red line). $\mathbf{b}$ Is similar to $\mathbf{a}$ but for eddy heat fluxes $\left(\rho_{0} C_{p} w^{\prime} T^{\prime}, C_{p}=4000 \mathrm{~J} \mathrm{~kg}^{-1}{ }^{\circ} \mathrm{C}^{-1}\right.$ is the ocean heat capacity). The grey lines represent zero

of the entire current feedback on eddy energetics come from two parts: the mesoscale eddy's current feedback on wind power and the large-scale current feedback on wind power (e.g., Duhaut and Straub 2006; Hughes and Wilson 2008). Since wind aligns with large-scale flows in the Kuroshio extension region, the wind power input to large-scale flows is evidently reduced in CTRL than noU ${ }_{\text {tot }}$. Specifically, the wind power input to the geostrophic large-scale flows decreases from $21.25 \mathrm{~mW} \mathrm{~m}^{-2}$ in noU ${ }_{\text {tot }}$ to $19.71 \mathrm{~mW} \mathrm{~m}^{-2}$ in CTRL, comparable to the change of $K_{\mathrm{m}} K_{\mathrm{e}}$ between these two experiments (Table 1). The reduced MKE injection by wind partly explains the weakening of $K_{\mathrm{m}} K_{\mathrm{e}}$ in CTRL than noU tot. As a response to the reduced $K_{\mathrm{m}} K_{\mathrm{e}}$, the intensification of $P_{\mathrm{e}} K_{\mathrm{e}}$ in DIFF2 is much more pronounced than that in DIFF1. The value of $P_{\mathrm{e}} K_{\mathrm{e}}$ in CTRL is 1.5 times as large as that in $\mathrm{noU}_{\mathrm{e}}$ while 2.4 times as large as that in noU $U_{\text {tot }}$.

\section{Conclusions}

Based on high-resolution coupled regional climate models, we assess the impacts of the current feedback on eddy energetics in the Kuroshio extension region. The major findings of our study are as follows:

1. The current feedback reduces the upper-1000 m EKE in the Kuroshio extension region with the reduction most evident at the sea surface $(\sim 20 \%)$. The reduced EKE is mainly attributed to the negative wind power input to mesoscale eddies due to the mesoscale eddy's current imprint on the wind stress.

2. When only the mesoscale eddy's current imprint on the wind stress is present, its resultant negative wind power on mesoscale eddies is compensated primarily by the enhanced conversion from MKE and EPE to EKE and secondarily by the reduced pressure flux divergence and horizontal dissipation.

3. Although both the mesoscale eddy's and the entire current feedbacks result in similar EKE variations, their effects on the EKE budget is different. The most noticeable discrepancy is that the MKE to EKE conversion is weakened rather than strengthened in response to the entire current feedback. This is partly because the reduced kinetic energy input to background flows by wind.

The enhanced EPE-EKE conversion [expressed as $-<w^{\prime} \rho^{\prime} g>$ in Eq. (2)] by the current feedback corresponds to an intensified upward eddy buoyancy flux (defined as $<w^{\prime} b^{\prime}>$, Fig. 4a). In the Kuroshio extension region, the variation of buoyancy is dominated by that of temperature. Thus, the upward eddy heat flux (defined as $<\rho_{0} C_{\mathrm{p}} w^{\prime} T^{\prime}>$, Fig. $4 \mathrm{~b}$ ) is strengthened as well, transporting more heat stored in the abyss into the upper ocean and may have potentially important influences on the ocean thermal structure. Due to the short integration time of our model simulations, such a conjecture cannot be examined but deserves further study 
in the future. Moreover, although EKE is a widely used measurement for mesoscale eddy activities (Stammer and Wunsch 1999; Qiu and Chen 2004; Jia et al. 2011), results in this study suggest that it is not necessarily related to the intensity of eddy transports. For instance, EKE is reduced as a response to the current feedback, whereas the opposite is true for the vertical eddy buoyancy/heat flux; EKE remains similar with and without the background flow's current feedback, but the vertical eddy buoyancy/heat flux differs substantially between the two situations. Thus there is no one-to-one correspondence between EKE level and the intensity of eddy transports.

\section{Supplementary information}

Supplementary information accompanies this paper at https://doi. org/10.1186/s40562-020-00152-w.

Additional file 1: Figure S1. The isolation of mesoscale variabilities. (a) A snapshot of EKE isolated by a Loess filter with a $15^{\circ}$ (longitude) $\times 5^{\circ}$ (latitude) half width in the Kuroshio extension region $\left(34^{\circ}-40^{\circ} \mathrm{N}, 144^{\circ}-155^{\circ} \mathrm{E}\right)$; (b) is similar to (a) but for the alternative filter we use in the paper. (c) The wavenumber spectrum of (a) and (b) denoted by the blue and red lines respectively.

\section{Abbreviations}

CRCM: Coupled regional climate model; CTRL: The fully coupled CRCM simulation; ECCO2: Estimating the Circulation and Climate of the Ocean (ECCO), Phase II; EKE:The eddy kinetic energy; EPE: The eddy available potential energy; HDK: The horizontal dissipation of EKE; MITgcm: Massachusetts Institute of Technology General Circulation Model; MKE: The kinetic energy of mean flows; noU $U_{\mathrm{e}}$ The CRCM simulation in which the mesoscale current is excluded in the wind stress calculation; no $U_{\text {tot }}$ : The CRCM simulation in which the entire surface current is excluded in the wind stress calculation; $K_{m} K_{e}$ : The energy conversion from MKE to EKE; PWork: The EKE divergence through pressure fluxes; $P_{\mathrm{e}} K_{\mathrm{e}}$ : The energy conversion from EPE to EKE; RHS: The right-hand side; ROMS: Regional Oceanic Modeling System (the ocean component of CRCM); SSTA: The sea surface temperature anomaly; TK $:$ The tendency of EKE; VDK $K_{e}$ The vertical dissipation of EKE; VIDK : The vertical interior dissipation of EKE; WP : The wind power input to mesoscale eddies; WRF: Weather Research and Forecasting Model (the atmosphere component of CRCM).

\section{Acknowledgements}

The Center for High Performance Computing and System Simulation, Pilot National Laboratory for Marine Science and Technology (Qingdao) is acknowledged for supporting the implement of our models.

\section{Authors' contributions}

XS proposed the central idea, conducted the analysis and wrote the manuscript under the instruction of ZJ. ZJ contributed to the idea and organized the writing of the manuscript. BS performed the CRCM simulations. LW contributed to the writing of the manuscript. All authors read and approved the final manuscript.

\section{Funding}

ZJ is supported by National Science Foundation of China (41822601, 41776006), Taishan Scholar Funds (tsqn201909052) and Fundamental Research Funds for the Central Universities $(201841011,201812014)$.

\section{Availability of data and materials}

The datasets used during the current study are available from the corresponding author on reasonable request.

\section{Competing interests}

The authors declare that they have no competing interests.

Received: 10 September 2019 Accepted: 14 February 2020

Published online: 20 March 2020

\section{References}

Bishop SP, Small RJ, Bryan FO, Tomas RA (2017) Scale dependence of midlatitude air-sea interaction. J Clim 30:8207-8221. https://doi.org/10.1175/ Jcli-D-17-0159.1

Chelton DB, Xie S (2010) Coupled ocean-atmosphere interaction at oceanic mesoscales. Oceanography 23:52-69. https://doi.org/10.5670/ocean og.2010.05

Chelton DB, Schlax MG, Freilich MH, Milliff RF (2004) Satellite measurements reveal persistent small-scale features in ocean winds. Science 303:978983. https://doi.org/10.1126/science.1091901

Chou MD, Suarez MJ (1994) An efficient thermal infrared radiation parameterization for use in general circulation models, vol 3. NASA Tech Memo, 104606. National Aeronautics and Space Administration, Greenbelt, p 85

Cornillon P, Park K (2001) Warm core ring velocities inferred from NSCAT. Geophys Res Lett 28:575-578. https://doi.org/10.1029/2000gl011487

Dawe JT, Thompson L (2006) Effect of ocean surface currents on wind stress, heat flux, and wind power input to the ocean. Geophys Res Lett 33:L09604. https://doi.org/10.1029/2006gl025784

Dewar WK, Flierl GR (1987) Some effects of the wind on rings. J Phys Ocean 17:1653-1667. https://doi.org/10.1175/1520-0485(1987)017\%3c165 3:seotwo\%3e2.0.co;2

Dong D, Brandt P, Chang P et al (2017) Mesoscale eddies in the northwestern Pacific Ocean: three-dimensional eddy structures and heat/ salt transports. J Geophys Res Ocean 122:9795-9813. https://doi. org/10.1002/2017JC013303

Duhaut THA, Straub DN (2006) Wind stress dependence on ocean surface velocity: implications for mechanical energy input to ocean circulation. J Phys Ocean 36:202-211. https://doi.org/10.1175/Jpo2842.1

Frenger I, Gruber N, Knutti R, Munnich M (2013) Imprint of Southern Ocean eddies on winds, clouds and rainfall. Nat Geosci 6:608-612. https://doi. org/10.1038/Ngeo1863

Gaube P, Chelton DB, Samelson RM et al (2015) Satellite observations of mesoscale eddy-induced Ekman pumping. J Phys Ocean 45:104-132. https://doi.org/10.1175/Jpo-D-14-0032.1

Griffies SM, Hallberg RW (2000) Biharmonic friction with a Smagorinskylike viscosity for use in large-scale eddy-permitting ocean models. Mon Weather Rev 128:2935-2946. https://doi.org/10.1175/15200493(2000)128\%3c2935:BFWASL\%3e2.0.CO;2

Hong S, Pan H (1996) Nonlocal boundary layer vertical diffusion in a medium-range forecast model. Mon Weather Rev 124:2322-2339. https://doi.org/10.1175/1520-0493(1996)124\%3c2322:nblvd i\%3e2.0.co;2

Hughes CW, Wilson C (2008) Wind work on the geostrophic ocean circulation: an observational study of the effect of small scales in the wind stress. J Geophys Res Oceans 113:C02016. https://doi.org/10.1029/2007jc004371

Jia F, Wu L, Qiu B (2011) Seasonal modulation of eddy kinetic energy and its formation mechanism in the Southeast Indian Ocean. J Phys Ocean 41:657-665. https://doi.org/10.1175/2010JPO4436.1

Kain JS (2004) The Kain-Fritsch convective parameterization: an update. J Appl Meteorol 43:170-181. https://doi.org/10.1175/15200450(2004)043\%3c0170:TKCPAU\%3e2.0.CO;2

Kang SK (2008) KORDI program for typhoon-ocean interaction in the shelf seas and Northwestern Pacific. In: 28th Conference on Hurricanes and Tropical Meteorology

Kelly KA, Dickinson S, McPhaden MJ, Johnson GC (2001) Ocean currents evident in satellite wind data. Geophys Res Lett 28:2469-2472. https:// doi.org/10.1029/2000gl012610

Kirtman BP, Bitz C, Bryan F et al (2012) Impact of ocean model resolution on CCSM climate simulations. Clim Dyn 39:1303-1328. https://doi. org/10.1007/s00382-012-1500-3 
Large WG, Mcwilliams JC, Doney SC (1994) Oceanic vertical mixing: a review and a model with a nonlocal boundary-layer parameterization. Rev Geophys 32:363-403. https://doi.org/10.1029/94RG01872

Li F, Sang H, Jing Z (2017) Quantify the continuous dependence of SST-turbulent heat flux relationship on spatial scales. Geophys Res Lett 44:63266333. https://doi.org/10.1002/2017gl073695

Lin Y, Farley RD, Orville HD (1983) Bulk parameterization of the snow field in a cloud model. J Clim Appl Meteorol 22:1065-1092. https://doi. org/10.1175/1520-0450(1983)022\%3c1065:bpotsf\%3e2.0.co;2

Ma X, Jing Z, Chang P et al (2016) Western boundary currents regulated by interaction between ocean eddies and the atmosphere. Nature 535:533-537. https://doi.org/10.1038/nature18640

Mlawer EJ, Taubman SJ, Brown PD et al (1997) Radiative transfer for inhomogeneous atmospheres: RRTM, a validated correlated-k model for the longwave. J Geophys Res 102:16663-16682. https://doi.org/10.1029/97JD0 0237

Oerder V, Colas F, Echevin V et al (2018) Impacts of the mesoscale oceanatmosphere coupling on the Peru-Chile ocean dynamics: the currentinduced wind stress modulation. J Geophys Res Oceans 123:812-833. https://doi.org/10.1002/2017jc013294

O'Neill LW, Esbensen SK, Thum N et al (2010) Dynamical analysis of the boundary layer and surface wind responses to mesoscale SST perturbations. J Clim 23:559-581. https://doi.org/10.1175/2009jcli2662.1

O'Neill LW, Chelton DB, Esbensen SK (2012) Covariability of surface wind and stress responses to sea surface temperature fronts. J Clim 25:5916-5942. https://doi.org/10.1175/Jcli-D-11-00230.1

Park K, Cornillon PC (2002) Stability-induced modification of sea surface winds over Gulf Stream rings. Geophys Res Lett 29:2211. https://doi org/10.1029/2001gl014236

Pedloski J (1987) Geophysical fluid dynamics, 2nd edn. Springer, Berlin

Qiu B, Chen S (2004) Seasonal modulations in the eddy field of the South Pacific Ocean. J Phys Ocean 34:1515-1527. https://doi.org/10.1175/15200485(2004)034\%3c1515:smitef\%3e2.0.co;2

Renault L, Molemaker MJ, McWilliams JC et al (2016) Modulation of wind work by oceanic current interaction with the atmosphere. J Phys Ocean 46:1685-1704. https://doi.org/10.1175/Jpo-D-15-0232.1

Renault L, Marchesiello P, Masson S, McWilliams JC (2019) Remarkable control of western boundary currents by eddy killing, a mechanical air-sea coupling process. Geophys Res Lett 46:2743-2751. https://doi. org/10.1029/2018GL081211

Seo G, Choi B, Cho Y et al (2010) Assimilation of sea surface temperature in the Northwest Pacific Ocean and its marginal seas using the ensemble Kalman filter. Ocean Sci J 45:225-242. https://doi.org/10.1007/s1260 1-010-0021-4

Seo H, Miller AJ, Norris JR (2016) Eddy-wind interaction in the California current system: dynamics and impacts. J Phys Ocean 46:439-459. https://doi. org/10.1175/Jpo-D-15-0086.1

Shan X, Jing Z, Gan B et al (2020) Surface heat flux induced by mesoscale eddies cools the Kuroshio-Oyashio Extension region. Geophys Res Lett. https://doi.org/10.1029/2019GL086050

Smagorinsky J (1963) General circulation experiments with the primitive equations. Mon Weather Rev 91:99-164. https://doi.org/10.1175/15200493(1963)091\%3c0099:GCEWTP\%3e2.3.CO;2

Stammer D, Wunsch C (1999) Temporal changes in eddy energy of the ocean. Deep-Sea Res 46:77-108. https://doi.org/10.1016/S0967-0645(98)00106-4

Vecchi GA, Xie S, Fischer AS (2004) Ocean-atmosphere covariability in the western Arabian Sea. J Clim 17:1213-1224. https://doi.org/10.1175/15200442(2004)017\%3c1213:Ocitwa\%3e2.0.Co;2

Xie S (2004) Satellite observations of cool ocean-atmosphere interaction. Bull Am Meteorol Soc 85:195-208. https://doi.org/10.1175/Bams-85-2-195

Xu Y, Scott RB (2008) Subtleties in forcing eddy resolving ocean models with satellite wind data. Ocean Model 20:240-251. https://doi.org/10.1016/j. ocemod.2007.09.003

Yang P, Jing Z, Wu L (2018) An assessment of representation of oceanic mesoscale eddy-atmosphere interaction in the current generation of general circulation models and reanalyses. Geophys Res Lett 45:11856-11865. https://doi.org/10.1029/2018gl080678

Zhai X, Greatbatch RJ (2007) Wind work in a model of the northwest Atlantic Ocean. Geophys Res Lett 34:L04606. https://doi.org/10.1029/2006gl0289 07

\section{Publisher's Note}

Springer Nature remains neutral with regard to jurisdictional claims in published maps and institutional affiliations.

\section{Submit your manuscript to a SpringerOpen ${ }^{\circ}$ journal and benefit from:}

- Convenient online submission

- Rigorous peer review

- Open access: articles freely available online

- High visibility within the field

Retaining the copyright to your article

Submit your next manuscript at springeropen.com 